\title{
Cyclic lipodepsipeptides verlamelin A and B, isolated from entomopathogenic fungus Lecanicillium sp.
}

\author{
Kei-ichi Ishidoh ${ }^{1}$, Hiroshi Kinoshita ${ }^{1}$, Yasuhiro Igarashi ${ }^{2}$, Fumio Ihara ${ }^{3}$ and Takuya Nihira ${ }^{1,4}$ \\ Verlamelin and its new derivative (verlamelin B) were isolated from fermentation broth of entomopathogenic fungus \\ Lecanicillium sp. HF627. As the structural elucidation of verlamelin so far was only preliminary, we studied and determined the \\ absolute structure of these two compounds to be cyclo(5S-hydroxytetradecanoic acid-D-alloThr/Ser-D-Ala-L-Pro-L-GIn-D-Tyr-L- \\ Val). This is the first study that precisely analyzed the structure of verlamelin.
}

The Journal of Antibiotics (2014) 67, 459-463; doi:10.1038/ja.2014.22; published online 2 April 2014

Keywords: cyclic lipodepsipeptide; entomopathogenic fungi; Lecanicillium; Verticillium lecanii

\section{INTRODUCTION}

Entomopathogenic fungi are fungal parasites of insects. During their infection to insects, they are known to evade insect immunities and kill the host insects by secreting several bioactive substances. ${ }^{1-3}$ As the high productivity has been well established by continuous discovery of novel bioactive compounds, ${ }^{4-6}$ entomopathogenic fungi have been regarded as a source of bioactive compounds. Especially, those belonging to the genus Lecanicillium (formerly Verticillium lecanii) can be good source of novel compounds, as exemplified by the isolation of indolosesquiterpenes (lecanindoles $\mathrm{A}-\mathrm{D}^{7}$ ), phenopicolinic acid derivatives (vertilecanins ${ }^{8}$ ) and pregnanes. ${ }^{9,10}$

Here we would like to report isolation and structure determination of two compounds, verlamelin (verlamelin A, 1) and it new derivative (verlamelin B, 2) from entomopathogenic fungus Lecanicillium sp. Although the planar structure of verlamelin has already been reported, its structure determination was only preliminary, because these reports lacked detailed information on the signal assignments of ${ }^{1} \mathrm{H} /{ }^{13} \mathrm{C}$, the signal connectivity in HSQC/HMBC and the $\mathrm{D} / \mathrm{L}$ configuration of the component amino acids. ${ }^{1-13}$ Furthermore, the configuration of a hydroxyl group on the 5-hydroxytetradecanoic acid moiety has not yet been determined. Therefore, in order to completely establish the structure of verlamelin, we conducted a detailed structure determination of 1 and 2 .

\section{RESULTS AND DISCUSSIONS}

Lecanicillium sp.

HF627 was cultivated under static conditions in liquid medium containing sucrose $8 \%$, yeast extract $4 \%, \mathrm{CaCO}_{3} 0.5 \%$ and $\mathrm{HP} 201 \%$. The whole broth was extracted with $n$-butanol. Compounds 1 and 2 were purified by a series of steps with silica gel column chromatography, C18 column chromatography and preparative reverse phase HPLCs.

Both major compound $\mathbf{1}$ and minor compound $\mathbf{2}$ were obtained as colorless solid. The molecular formula of 1 was identified as $\mathrm{C}_{45} \mathrm{H}_{71} \mathrm{~N}_{7} \mathrm{O}_{11}$ based on high-resolution fast atom bombardment MS (HRFABMS) (observed $\mathrm{m} / \mathrm{z} 886.5289[\mathrm{M}+\mathrm{H}]^{+}$, calcd 886.5290 for $\left.\mathrm{C}_{45} \mathrm{H}_{72} \mathrm{~N}_{7} \mathrm{O}_{11}\right)$. The molecular formula of 2 was $\mathrm{C}_{44} \mathrm{H}_{69} \mathrm{~N}_{7} \mathrm{O}_{11}$ (HRFABMS, observed $\mathrm{m} / \mathrm{z} 872.5140[\mathrm{M}+\mathrm{H}]^{+}$, calcd 872.5134 for $\left.\mathrm{C}_{44} \mathrm{H}_{70} \mathrm{~N}_{7} \mathrm{O}_{11}\right)$, suggesting that 2 is a one-methylene-shorter derivative of 1 , considering the almost identical UV/Vis spectrum $\left(\lambda_{\max } 224\right.$, $278 \mathrm{~nm})$.

All the ${ }^{13} \mathrm{C}$ signals and all the ${ }^{1} \mathrm{H}$ signals were assigned using DEPT135, HSQC, COSY and HMBC (Table 1). ${ }^{13} \mathrm{C}$ NMR of the two compounds detected eight carbonyl carbons in the range of $\delta_{\mathrm{C}}$ 170-174, and ${ }^{1} \mathrm{H}$ NMR in DMSO- $\mathrm{d}_{6}$ revealed eight broad resonances, which were not detectable in the measurement using methanol- $\mathrm{d}_{4}$, suggesting that certain numbers of amide linkages were present in these compounds. Overlapping methylene signals in the high magnetic field suggested that both compounds have an alkyl chain. Based on these data, $\mathbf{1}$ and $\mathbf{2}$ were assumed to bear typical lipopeptide substructures. By COSY and HMBC correlations, the component amino acids were estimated to be valine (Val), alanine (Ala), tyrosine (Tyr), threonine (Thr) (1) or serine (Ser) (2), glutamine (Gln) and proline (Pro). The remaining substructure was deduced to be a 5 -hydroxytetradecanoic acid moiety by comparison of the $\delta \mathrm{c}$ values of C-2 to C-6 with those on cordycommunin, which has the 5-hydroxytetradecanoic acid substructure. ${ }^{14}$ As $\delta_{\mathrm{H}}$ of the oxymethine H-5 was detected relatively downfield (4.79 (1), 4.77 (2)), the C-5 was judged to be involved in ester bonding. The connecting sequence of components was finally determined as

\footnotetext{
${ }^{1}$ International Center for Biotechnology, Osaka University, Osaka, Japan; ${ }^{2}$ Biotechnology Research Center, Toyama Prefectural University, Toyama, Japan; ${ }^{3}$ National Institute of Fruit Tree Science, Ibaraki, Japan and ${ }^{4}$ Mahidol University-Osaka University Collaborative Research Center for Bioscience and Biotechnology, Faculty of Science, Mahidol University, Bangkok, Thailand

Correspondence: Professor T Nihira, Mahidol University-Osaka University Collaborative Research Center for Bioscience and Biotechnology, Faculty of Science, Mahidol University, 272 Rama VI Road, Ratchathewi, Bangkok 10400, Thailand.

E-mail:nihira@icb.osaka-u.ac.jp
}

Received 19 November 2013; revised 26 February 2014; accepted 5 March 2014; published online 2 April 2014 
Table 1 NMR spectroscopic data (400 MHz, DMSO-d6) for verlamelin A (1) and verlamelin B (2)

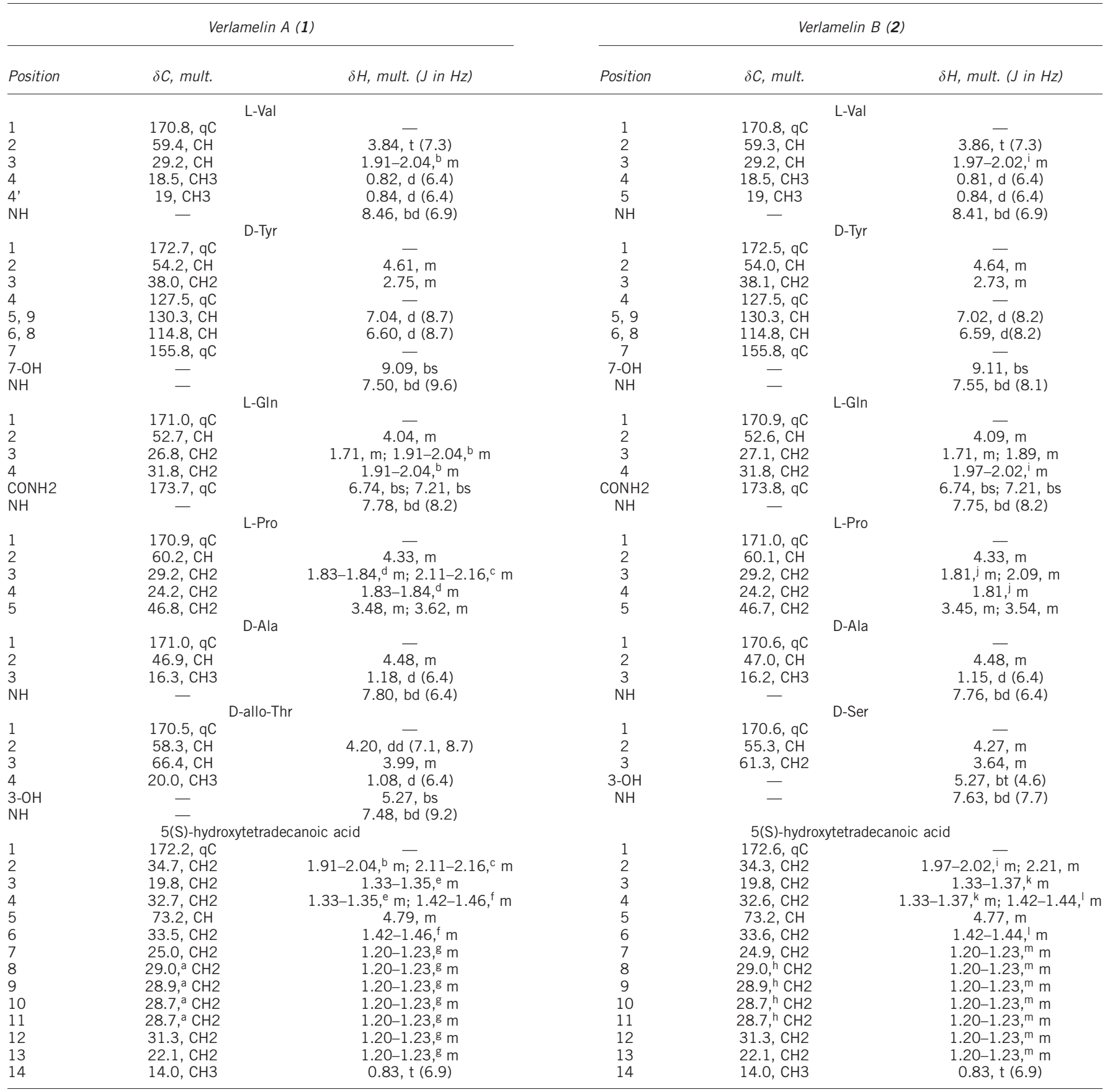

${ }^{\mathrm{a}, \mathrm{h}}$ Carbon chemical shifts may be interchanged.

$\mathrm{b}, \mathrm{c}, \mathrm{d}, \mathrm{e}, \mathrm{f}, \mathrm{g}, \mathrm{i}, \mathrm{j}, \mathrm{k}, \mathrm{l}, \mathrm{l}, \mathrm{m} T$ The proton resonances are overlapped.

5-hydroxytetradecanoic acid, Thr (1) or Ser (2), Ala, Pro, Gln, Tyr and Val, based on HMBC and ROESY (1) and NOESY (2) correlation. HMBC correlation of the oxymethine on 5hydroxytetradecanoic acid with $\mathrm{C}-1$ on Val demonstrated the formation of a cyclic structure (Figure 1). Thus, the compound 2 was proposed to be a new analog of verlamelin (verlamelin B) in which Ser was replaced with Thr.

To determine the absolute configurations in the peptide moiety of the verlamelins, Marfey's analysis was conducted. ${ }^{15}$ After degradation of verlamelin A and verlamelin B under acidic conditions, the hydrolysate was labeled by Marfey's reagent ( $\mathrm{N} \alpha$-(5-Fluoro-2,4dinitrophenyl)-L-alaninamide). The retention times of the labeled products in C18 HPLC (29.3, 30.2, 34.5, 37.3, 40.4, 42.1, $62.2 \mathrm{~min}$ for verlamelin $\mathrm{A}$; and $26.0,30.2,34.6,37.3,40.5,42.2,62.2 \mathrm{~min}$ for verlamelin B) indicated that the component amino acids were L-Gln, L-Pro, D-Ala, L-Val, D-Tyr and D-allo-Thr (verlamelin A) or D-Ser (verlamelin B) (see 'Experimental procedure' for standards).

As for the absolute configuration of C-5 in the 5-hydroxytetradecanoic acid moiety, a modified Mosher's method was used. ${ }^{16,17}$ After the reactive phenolic hydroxyl group was protected by methyl iodide 


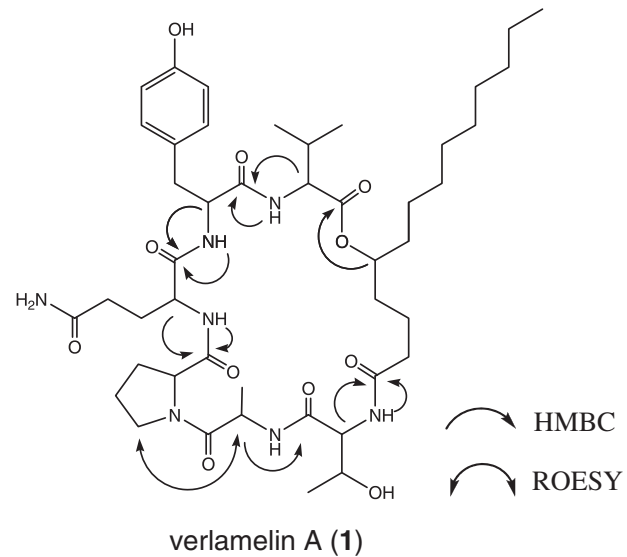

Figure 1 Key HMBC, ROESY (1) and NOESY (2) correlation.

(R) - (S) (ppm)

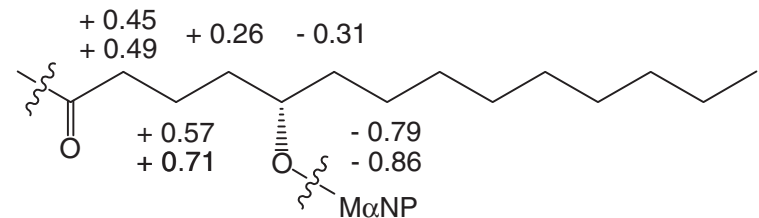

Derivative of (1)

(R) - (S) (ppm)

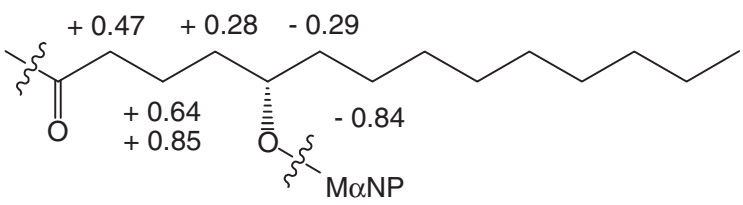

Derivative of (2)

Figure 2 Partial (R)-(S) values of derivatives of (1) and (2) synthesized by a modified Mosher's method.

and the macrolactone ring was cleaved by methanolysis, the reaction products (purified by C18 HPLC) showed $\mathrm{m} / \mathrm{z}$ at 932.5 and 918.5 , respectively, suggesting that methanolysis proceeded successfully. Reaction of the product from 1 with (R)- or (S)-M $\alpha \mathrm{NP}$ acid (M.W.: 230.2) gave products (purified by C18 HPLC) of $\mathrm{m} / \mathrm{z}$ at 1144.6, implying that the esterification with M $\alpha \mathrm{NP}$ occurred at a single position. Similar esterification reaction of the product from 2 gave products of $\mathrm{m} / \mathrm{z} 1342.7$, suggesting that the two molecules of $\mathrm{M} \alpha \mathrm{NP}$ were incorporated. Subsequent partial hydrolysis with $\mathrm{K}_{2} \mathrm{CO}_{3}$ resulted in the loss of one M $\alpha \mathrm{NP}$ at the primary alcohol of the Ser residue and yielded a product of $\mathrm{m} / \mathrm{z}$ at 1112.6, corresponding to the monoester with an M $\alpha$ NP. Each monoester with an M $\alpha$ NP was analyzed by ${ }^{1} \mathrm{H}$ NMR and COSY to observe the anisotropic effect as the result of shielding by the M $\alpha \mathrm{NP}$ group. The $\Delta \delta(\delta \mathrm{R}-\delta \mathrm{S})$ values of the Mosher's esters indicated the 5-S configuration (Figure 2). Based on these results, the absolute structures of verlamelin A and verlamelin B were definitively determined for the first time, as shown in Figure 3.

Based on the previous results of in vitro antifungal activity of verlamelin, ${ }^{11-13}$ we measured the antifungal activity of $\mathbf{1}$ and $\mathbf{2}$ by disc diffusion method (summary of results, Supplementary Figure S11).

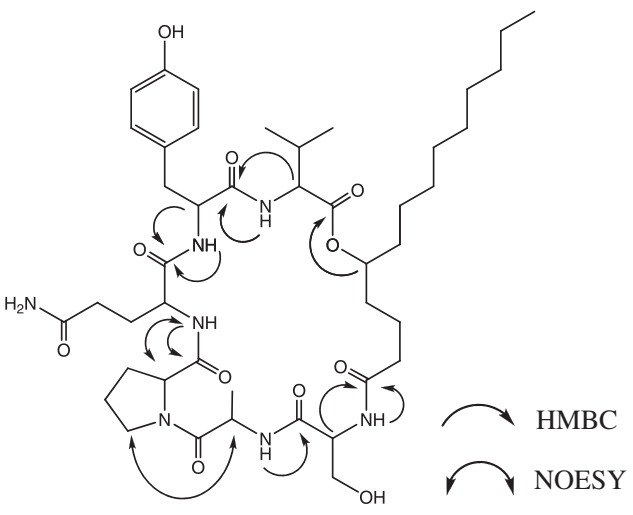

verlamelin B (2)

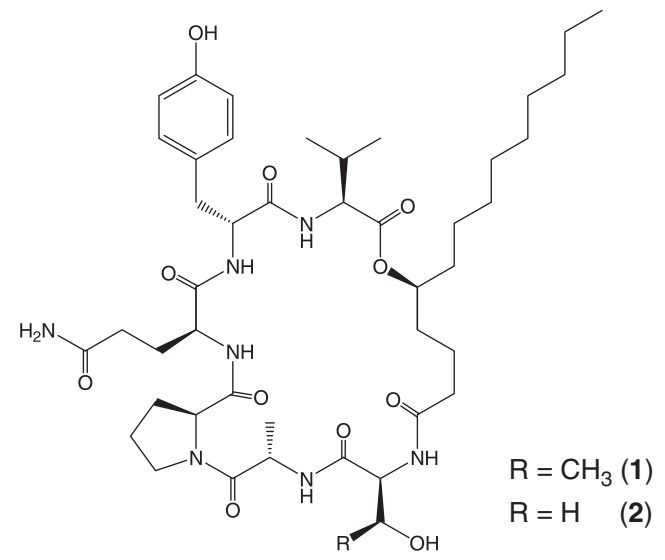

Figure 3 Stereochemical structure of verlamelin A (1) and B (2), refined in this study.

The potency of both compounds was equal when tested against Cochliobolus miyabeanus and Alternalia solani. However, the new derivative of verlamelin, 2 was less active against Fusarium oxysporum, Cladosporium cucumerinum and Ustilago maydis (potency of 2: 4, 0.5 and $>64 \mu \mathrm{g}$ per disc, respectively), compared with 1 (potency of $1: 2$, 0.25 and $16 \mu \mathrm{g}$ per disc, respectively), suggesting that the methyl group on the first amino-acid residue connected to the fatty acid moiety should have an important role for antifungal activities against these fungi. As antifungal spectrum of 1 agreed well with that of the verlamelin reported previously, ${ }^{13} 1$ might possess identical absolute configuration to that of the original verlamelin.

By detailed structure determination, the absolute structures of $\mathbf{1}$ and 2 were identified for the first time; they were found to consist of a cyclic lipodepsipeptide, cyclo(5S-hydroxytetradecanoic acid-DalloThr/Ser-D-Ala-L-Pro-L-Gln-D-Tyr-L-Val) (Figure 3). The related compounds, W493 A/B, cyclo(3S-hydroxy-4R-methyltetradecanoic acid-D-alloThr-L-Ala-D-Ala-L-Gln-D-Tyr-L-Val/Ile), from Fusarium sp., ${ }^{18}$ and cordycommunin, cyclo(5-hydroxytetradecanoic acid-D-alloThr-L-Ala-L-Ala-L-Gln-L-Tyr-L-Val), from Ophiocordyceps communis, ${ }^{14}$ have also similar partial structure to fengycin (plilastatin $\mathrm{A} 1$, inhibitor of phospholipase $\mathrm{A}_{2}$ ), which was isolated from Bacillus subtilis as an antifungal lipopeptide compound containing a cyclic peptide moiety composed of L-Tyr-D-alloThr-L-Glu-D-Ala-L-Pro-LGln-D-Tyr-L-Ile. ${ }^{19,20}$ Judging from the correlation of the structure 
and the antifungal activity among these cyclic peptide compounds, D-tyrosine after L-glutamine might be critical for antifungal activities because cordycommunin, which possesses L-Tyr instead of D-Tyr, did not show activity against Candida albicans and Magnaporthe grisea. ${ }^{14}$

\section{EXPERIMENTAL PROCEDURE}

\section{General experimental procedure}

NMR spectra were recorded on a JEOL JMN-ECS400 (JEOL, Tokyo, Japan) at $400 \mathrm{MHz}$ for ${ }^{1} \mathrm{H}$ and $100 \mathrm{MHz}$ for ${ }^{13} \mathrm{C}$. The ${ }^{1} \mathrm{H}$ and ${ }^{13} \mathrm{C}$ chemical shifts were referenced to the solvent signal $(\delta \mathrm{H} 2.49$ and $\delta \mathrm{C} 39.5$ in dimethyl sulfoxide (DMSO)-d6, $\delta \mathrm{H} 3.31$ in $\mathrm{CD}_{3} \mathrm{OD}$ ). HRFABMS were recorded on a JEOL JMS700 spectrometer. Optical rotation was measured on a P-1020 polarimeter (Jasco, Tokyo, Japan). The UV spectrum was recorded on a Hitachi U-3200 spectrophotometer (Hitachi, Tokyo, Japan).

\section{Fungal material}

The entomopathogenic fungus Lecanicillium sp. HF627 was isolated from a chillie thrips cadaver. Fungal conidia that had developed on the surface of the cadaver were transferred onto solid Sabouraud maltose yeast-extract (SMY) medium ( $4 \%$ maltose, $1 \%$ yeast extract, $1 \%$ peptone) with $1.5 \%$ agar and incubated at $25^{\circ} \mathrm{C}$ for several days. After several rounds of single-colony isolation, the isolated strain was identified as Verticillium lecanii (Lecanicillium sp.) according to its morphology. The fungus is deposited at the culture collection of Natural Institute of Fruit Tree Science.

\section{Fermentation and isolation}

The seed culture was prepared by inoculating conidia of strain HF627 into $50 \mathrm{ml}$ of SMY medium in a $500-\mathrm{ml}$ baffled flask, followed by cultivation on a rotatory shaker at $28^{\circ} \mathrm{C}$ and 160 r.p.m. for 3 days. For the main cultivation, the seed culture $(2 \mathrm{ml})$ was inoculated into $100 \mathrm{ml}$ of Medium \#5 (8\% sucrose, $4 \%$ yeast extract, $0.5 \% \mathrm{CaCO}_{3}, 1 \%$ activated HP20 (Mitsubishi Chemical Co., Tokyo, Japan) by methanol) in 500-ml Erlenmeyer flasks, followed by static incubation for 21 days at $25^{\circ} \mathrm{C}$. The culture broth ( 1 liter) was mixed with $n$ butanol $(500 \mathrm{ml})$ and stirred for $1 \mathrm{~h}$, and the $n$-butanol layer was collected after centrifugation (3000 r.p.m., $10 \mathrm{~min}$ ), dried over anhydrous sodium sulfate and concentrated in vacuo using a rotary evaporator, yielding $3 \mathrm{~g}$ of brown gum as the crude extract. The crude extract was fractionated on a silica gel 60 (70-230 mesh; Merck, Darmstadt, Germany) column $(\varnothing 30 \mathrm{~mm})$ by stepwise elution with increasing ethyl acetate concentrations (hexane/ethyl acetate $=4: 1,2: 1$, $3: 2,1: 1,1: 2,1: 4$ and $0: 10 \mathrm{v} / \mathrm{v}$ ), followed by stepwise elution with increasing methanol concentrations (ethyl acetate/methanol $=40: 1,20: 1,10: 1,8: 1,4: 1$, $2: 1,1: 1$, and $0: 10 \mathrm{v} / \mathrm{v})$. Fractions containing verlamelins were detected by silica gel TLC (ethyl acetate/methanol=2:1, Rf 0.21), combined and evaporated in vacuo until dryness. The residues were further fractionated with a Sep-Pak Silica $35 \mathrm{cc}$ Vac cartridge ( $10 \mathrm{~g}$; Waters, Milford, MA, USA) by stepwise elution with increasing methanol concentrations (ethyl acetate/methanol $=2: 1,3: 2$, $1: 1,1: 2,1: 4$, and $0: 10 \mathrm{v} / \mathrm{v}$ ). Verlamelins in the Sep-Pak fractions were further separated by preparative reverse phase HPLC with a Shiseido Capcell-Pak C18 column $(\varnothing 10 \times 250 \mathrm{~mm})$ (Shiseido Co., LTD., Tokyo, Japan) with isocratic elution using $80 \%$ methanol at a flow rate of $4 \mathrm{ml} \mathrm{min}^{-1}$. The peaks of 2 and 1, detected at 11 and $12 \mathrm{~min}$ by UV $(210 \mathrm{~nm})$, respectively, were collected individually and evaporated in vacuo to dryness, yielding 2.7 and $65.5 \mathrm{mg}$ of colorless amorphous solid, respectively (chromatogram of HPLC, see Supplementary Figure S1).

Additional quadruplicate experiments without the Sep-Pak Silica fractionation were carried out further to obtain 2 . As a result, a total of $97.7 \mathrm{mg}$ of $\mathbf{2}$ was obtained.

Compound (1): a colorless solid; $[\alpha]^{23} \mathrm{D}+2.5$ (c $\left.0.01, \mathrm{MeOH}\right)$; UV $(\mathrm{MeOH}) \lambda_{\max }(\log \varepsilon) 224$ (4.20), 278 (3.29) nm; HRFABMS m/z 886.5289 $[\mathrm{M}+\mathrm{H}]^{+}$(calcd for $\mathrm{C}_{45} \mathrm{H}_{72} \mathrm{~N}_{7} \mathrm{O}_{11}, 886.5290$ ). For ${ }^{1} \mathrm{H},{ }^{13} \mathrm{C}$, see Table 1 (see also Supplementary Figures S2 and S3).

Compound (2): a colorless solid; $[\alpha]^{23}{ }_{\mathrm{D}}-68.5$ (c $\left.0.01, \mathrm{MeOH}\right)$; UV $(\mathrm{MeOH}) \lambda_{\max }(\log \varepsilon) 224$ (4.12), $278(3.26) \mathrm{nm} ;$ HRFABMS m/z 872.5140 $[\mathrm{M}+\mathrm{H}]^{+}$(calcd for $\mathrm{C}_{44} \mathrm{H}_{70} \mathrm{~N}_{7} \mathrm{O}_{11}, 872.5134$ ). For ${ }^{1} \mathrm{H},{ }^{13} \mathrm{C}$, see Table 1 (see also Supplementary Figures S4 and S5).
Stereochemistry of amino acids constituting verlamelin A and B One milligram of aliquots of 1 or 2 were hydrolyzed by heating at $115^{\circ} \mathrm{C}$ for $8 \mathrm{~h}$ in $10 \mathrm{ml}$ of $6 \mathrm{M} \mathrm{HCl}$. After cooling to room temperature, they were completely dried in vacuo and dissolved in $150 \mu \mathrm{l}$ of water. Marfey's reagent $\left(300 \mu \mathrm{l}\right.$ of $10 \mathrm{mg} \mathrm{ml}^{-1}$ solution in acetone) $\left(\mathrm{N}^{\alpha}\right.$-(2,4-dinitro-5-fluorophenyl)-L-alaninamide) (Tokyo Chemical Industry Co., Ltd., Tokyo, Japan) was added, followed by the addition of $70 \mu \mathrm{l}$ of $1 \mathrm{M} \mathrm{NaHCO}_{3}$. The reactions proceeded at $37^{\circ} \mathrm{C}$ for $1 \mathrm{~h}$ and were quenched by addition of $70 \mu \mathrm{l}$ of $1 \mathrm{M} \mathrm{HCl}$. The resulting mixture was dried in vacuo and then dissolved in $1 \mathrm{ml}$ of DMSO to be analyzed by HPLC. Marfey's derivatives of amino acids as a standard were prepared by reacting $50 \mathrm{~mm}$ of amino acids in the same manner as described above. HPLC analysis was carried out on a Shiseido Capcell-Pak C18 column $(\varnothing 4.6 \times 250 \mathrm{~mm})$ with a linear gradient of $\mathrm{CH}_{3} \mathrm{CN}$ from $10 \%$ to $50 \%$ in $0.05 \%$ aqueous TFA solution ( $60 \mathrm{~min}$ from $10 \%$ to $50 \%, 5 \mathrm{~min}$ at $50 \%, 3 \mathrm{~min}$ from $50 \%$ to $10 \%$ ), at a flow rate of $1.0 \mathrm{ml} \mathrm{min}^{-1}$, with detection at $340 \mathrm{~nm}$. The glutamine (Gln) residues of $\mathbf{1}$ and $\mathbf{2}$ should be converted by acid hydrolysis to glutamic acid (Glu). Retention times (min) of Marfey's derivatives used as standards were as follows: L-Ser (25.6), D-Ser (26.0), L-Thr (27.0), D-Thr (31.8), L-alloThr (27.5), D-alloThr (29.3), L-Glu (30.1), D-Glu (31.9), L-Pro (34.3), D-Pro (36.0), L-Ala (33.2), D-Ala (37.2), L-Val (42.1), D-Val (48.1), L-Tyr (57.9) and D-Tyr $(40.4,62.2)$.

\section{(R)- and (S)-M $\alpha \mathrm{NP}$ acid ester derivatives of 1 and 2}

A modified Mosher's method using (R)- and (S)-M $\alpha$ NP acid (Tokyo Chemical Industry Co., Ltd.) was used to clarify the stereogenic centers of the hydroxytetradecanoic acid moiety. ${ }^{16}$ To protect the hydroxyl group of the Tyr residue in advance, methylation was carried out as follows. To 1 and 2 dissolved in acetonitrile $(10 \mathrm{mg}$ per $500 \mu \mathrm{l})$ were added $50 \mu \mathrm{l}$ of 1,8 diazabicyclo[5.4.0] undec-7-ene and $50 \mu \mathrm{l}$ of $\mathrm{CH}_{3} \mathrm{I}$. After incubation at $50^{\circ} \mathrm{C}$ for $3 \mathrm{~h}$ and quenching by dilution with water, the reaction products were extracted three times with an equal volume of ethyl acetate. The ethyl acetate layer was washed with $1 \mathrm{M} \mathrm{HCl}$ and brine, dried over anhydrous sodium sulfate, and concentrated in vacuo, yielding crude methyl ethers of $\mathbf{1}$ and $\mathbf{2}$.

To cleave the ester linkage between hydroxytetradecanoic acid and Val residue, methanolysis was carried out as follows. Crude verlamelin methyl ethers were dissolved in $2 \mathrm{ml}$ of $0.5 \mathrm{M}$ methanolic sodium metoxide and stirred for $5 \mathrm{~h}$ at room temperature. After quenching with $1 \mathrm{M} \mathrm{HCl}$, extraction with ethyl acetate (equal volume, three times) and evaporation in vacuo, the cleaved product and the uncleaved reactant were collected individually by reverse phase C18 HPLC using 85\% methanol as eluent. The recovered reactant was reused for the same reaction, and the product was obtained as described above. The methyl ethers of $\mathbf{1}$ and $\mathbf{2}$ yielded 6.2 and $4.2 \mathrm{mg}$ of methanolysis products, respectively.

(R)- and (S)-M $\alpha$ NP acid esters of 1 were prepared as follows. The methanolysis product of $\mathbf{1}$ methyl ether (in $200 \mu \mathrm{l}$ of $\mathrm{CH}_{2} \mathrm{Cl}_{2}$ ) was mixed with $2 \mathrm{mg}$ of dimethyl amino pyridine, $3 \mathrm{mg}$ of 1-ethyl-3-(3-dimethylaminopropyl) carbodiimide (EDC), $2 \mu \mathrm{l}$ of triethyl amine and $2.1 \mathrm{mg}$ of (R)-M $\alpha \mathrm{NP}$ acid or $2.1 \mathrm{mg}$ of (S)-M $\alpha \mathrm{NP}$ acid. After standing at room temperature overnight and quenching by addition of water, the reaction mixture was extracted three times with an equal volume of ethyl acetate. After washing the ethyl acetate extract with $1 \mathrm{~m} \mathrm{HCl}$ and brine, drying over anhydrous sodium sulfate and concentrating in vacuo, the (R)- and (S)-M $\alpha$ NP acid ester derivatives of $\mathbf{1}$ ( $\mathbf{3} \mathbf{a}$ and $\mathbf{3 b}$, respectively) were purified by reverse phase HPLC on a Shiseido Capcell-Pak C18 column $(\varnothing 10 \times 250 \mathrm{~mm})$ with isocratic elution using $90 \%$ methanol as a mobile phase.

(R)- and (S)-M $\alpha \mathrm{NP}$ acid ester derivatives of $\mathbf{2}$ ( $\mathbf{4 a}$ and $\mathbf{4 b}$, respectively) were synthesized and purified in a similar manner as those of $\mathbf{1}$.

Compund 3a: HRFABMS m/z $1144.6558 \quad[\mathrm{M}+\mathrm{H}]^{+}$(calcd for $\mathrm{C}_{61} \mathrm{H}_{90} \mathrm{~N}_{7} \mathrm{O}_{14}, 1144.6546$ ). For ${ }^{1} \mathrm{H}$, see Supplementary Figures $\mathrm{S} 6$ and S7. Compund 3b: HRFABMS $\mathrm{m} / \mathrm{z} \quad 1144.6543 \quad[\mathrm{M}+\mathrm{H}]^{+}$(calcd for $\left.\mathrm{C}_{61} \mathrm{H}_{90} \mathrm{~N}_{7} \mathrm{O}_{14}, 1144.6546\right)$. For ${ }^{1} \mathrm{H}$, see Supplementary Figures $\mathrm{S} 6$ and S8.

Compund 4a: HRFABMS $\mathrm{m} / \mathrm{z} \quad 1112.6274 \quad[\mathrm{M}+\mathrm{H}]^{+}$(calcd for $\mathrm{C}_{60} \mathrm{H}_{86} \mathrm{~N}_{7} \mathrm{O}_{13}, 1112.6283$ ). For ${ }^{1} \mathrm{H}$, see Supplementary Figures $\mathrm{S} 6$ and S9.

Compund 4b: HRFABMS $\mathrm{m} / \mathrm{z} \quad 1112.6284 \quad[\mathrm{M}+\mathrm{H}]^{+}$(calcd for $\left.\mathrm{C}_{60} \mathrm{H}_{86} \mathrm{~N}_{7} \mathrm{O}_{13}, 1112.6283\right)$. For ${ }^{1} \mathrm{H}$, see Supplementary Figures S6 and S10. 


\section{Antifungal assay}

In vitro antifungal activity of $\mathbf{1}$ and $\mathbf{2}$ against six indicator strains (Fusarium oxysporum subsp. cucumerinum NBRC 31224, Cladosporium cucumerinum NBRC 6370, Aspergillus niger NBRC 105649, Alternaria solani NBRC 7516, Cochliobolus miyabeanus NBRC 9633 and Ustilago maydis NBRC 6907) was tested by disc diffusion method as follows. Paper discs loaded with $10 \mu \mathrm{l}$ of verlamelin solution in DMSO were placed on the potato dextrose agar (Difco, Detroit, MI, USA) plate, which was homogeneously inoculated with conidia, myceria or vegetative culture of the indicator strains in advance. Growthinhibitory effect was observed after incubation at $28^{\circ} \mathrm{C}$ for $1-3$ days, depending on indicator strains. Nystatin $(16 \mu \mathrm{g}$ per disc $)$ and DMSO alone were used as the positive and negative controls, respectively.

1 Wang, B., Kang, Q., Lua, Y., Bai, L. \& Wanga, C. Unveiling the biosynthetic puzzle of destruxins in Metarhizium species. Proc. Natl Acad. Sci. USA 109, 1287-1292 (2012).

$2 \mathrm{Xu}, \mathrm{Y}$. et al. Biosynthesis of the cyclooligomer depsipeptide bassianolide, an insecticidal virulence factor of Beauveria bassiana. Fungal Genet. Biol. 46, 353-364 (2009).

$3 \mathrm{Xu}, \mathrm{Y}$. et al. Biosynthesis of the cyclooligomer depsipeptide beauvericin, a virulence factor of the entomopathogenic fungus Beauveria bassiana. Chem. Biol. 15, 898-907 (2008).

4 Azumi, M. et al. Aurovertins F-H from the entomopathogenic fungus Metarhizium anisopliae. J. Nat. Prod. 71, 278-280 (2008).

5 Isaka, M., Palasarn, S., Tobwor, P., Boonruangprapa, T. \& Tasanathai, K. Bioactive anthraquinone dimers from the leafhopper pathogenic fungus Torrubiella sp. BCC 28517. J. Antibiot. 65, 571-574 (2012).

6 Putri, S. P., Kinoshita, H., Ihara, F., Igarashi, Y. \& Nihira, T. Farinomalein, a maleimidebearing compound from the entomopathogenic fungus Paecilomyces farinosus. J. Nat. Prod. 72, 1544-1546 (2009).
7 Roll, D. M. et al. The Lecanindoles, nonsteroidal progestins from the terrestrial fungus Verticillium lecanii 6144. J. Nat. Prod. 72, 1944-1948 (2009).

8 Soman, A. G., Gloer, J. B., Angawi, R. F., Wicklow, D. T. \& Dowd, P. F. Vertilecanins: new phenopicolinic acid analogues from Verticillium lecanii. J. Nat. Prod. 64, 189-192 (2001).

9 Claydon, N., Grove, J. F., Pople, M. \& Begley, M. J. New metabolic products of

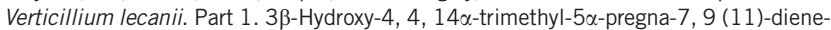
20S-carboxylic acid and the isolation and characterisation of some minor metabolites. J. Chem. Soc. Perkin Trans. 1, 497-502 (1984).

10 Grove, J. F. 23, 24, 25, 26, 27-Pentanorlanost-8-en-3ß, 22-diol from Verticillium lecanii. Phytochemistry 23, 1721-1723 (1984).

11 Onishi, J. C., Rowin, G. L. \& Miller, J. E. Antibiotic A43F. United States Patent 4201771. May 6 (1980).

$12 \mathrm{Kim}$, J. C. et al. Verlamelin, an antifungal compound produced by a mycoparasite Acremonium strictum. Plant Pathol. J. 18, 102-105 (2002).

13 Rowin, G. L. et al. Verlamelin, a new antifungal agent. J. Antibiot. 39, 1772-1775 (1986).

14 Haritakun, R., Sappan, M., Suvannakad, R., Tasanathai, K. \& Isaka, M. An antimycobacterial cyclodepsipeptide from the entomopathogenic fungus Ophiocordyceps communis BCC 16475. J. Nat. Prod. 73, 75-78 (2010).

15 Bhushan, R. \& Bruckner, H. Marfey's regent for chiral amino acid analysis: a review. Amino acids 27, 231-247 (2004).

16 Kasai, Y. et al. M $\alpha$ NP acid, a powerful chiral molecular tool for preparation of enantiopure alcohols by resolution and determination of their absolute configurations by the ${ }^{1}$ H NMR anisotropy method. Chirality 16, 569-585 (2004).

17 Kusumi, T., Yabuuchi, T., Takahashi, H. \& Ooi, T. Chiral anisotropic reagents for determining the absolute configulation of secondary alcohols and carboxylic acids. Yuki Gosei Kagaku Kyokaishi 63, 1102-1114 (2005).

18 Nihei, K., Itoh, H., Hashimoto, K., Miyairi, K. \& Okuno, T. Antifungal cyclodepsipeptides, W493 A and B, from Fusarium sp.: isolation and structural determination. Biosci. Biotechnol. Biochem. 62, 858-863 (1998).

19 Honma, M. et al. Termination of the structural confusion between plipastatin A1 and fengycin IX. Bioorg. Med. Chem. 20, 3793-3798 (2012).

20 Samel, S. A., Wagner, B., Marahiel, M. A. \& Essen, L. O. The thioesterase domain of the fengycin biosynthesis cluster: a structural base for the macrocyclization of a nonribosomal lipopeptide. J. Mol. Biol. 359, 876-889 (2006).

Supplementary Information accompanies the paper on The Journal of Antibiotics website (http://www.nature.com/ja) 